\title{
Awareness of the Food-Based Diet Guidelines, Eating Practices, and Preferred Sources of Nutrition Information of Employees in an Open University in the Philippines
}

\author{
Myra D. Oruga* $\odot$, Jelaine R. Bagos \\ University of the Philippines Open University, Los Baños, Laguna, Philippines
}

\begin{abstract}
Background: Physical inactivity and unhealthy diet are considered as major risk factors in the development of the "fatal four" Non-communicable Diseases (NCDs) (WHO, 2018). As the University of the Philippines Open University (UPOU) adopts a sedentary work lifestyle with most of the employees spending long hours at the office sitting in front of a computer screen, the university must be able to promote health and wellness in the workplace, particularly healthy eating.

Purpose: Thus, the study aimed to determine UPOU employees' awareness of the Food-based Dietary Guidelines (FBDGs), adherence to the 2012 Nutritional Guidelines for Filipinos (NGF), and preferred sources of information on healthy eating to provide insights for the development of nutrition interventions in the university.

Methods: A total of 85 healthy employees aged $19-59$ years old accomplished an online adapted survey from February to April 2019 which included questions on awareness of the four FBDGs--2012 NGF; Kumainments (simplified version of NGF); Daily Nutritional Guide Pyramid (DNGP); and Pinggang Pinoy (a plate-like pictorial model), eating practices relative to the 2012 NGF, and preferred sources of information on the FBDGs. Data were analyzed using descriptive statistics.

Results: Results of the study showed that most of the respondents were not aware of the FBDGs. Among those who were aware, only a few have read the FBDGs. Adherence to the guidelines was also low as reflected by a very low percentage of respondents practicing the messages on the recommended frequency of intake of food groups.

Conclusion: Results suggest conducting lectures or seminars and producing video materials about nutrition which can be uploaded in UPOU's online repository of multimedia resources and social media sites to promote healthy eating practices among UPOU employees and ensure a healthy and sustainable workforce.
\end{abstract}

Keywords: eating practices; FBDGs awareness; Open University Philippines; preferred information sources.

\section{Introduction}

Non-communicable diseases (NCDs), also known as chronic diseases, are non-infectious medical conditions which last for a long period of time and generally progress in a slow manner. These diseases can develop as a result of the confluence of genetic, physiological, environmental, and behavioural factors. Cardiovascular diseases such as heart attacks and stroke; cancers; chronic respiratory diseases like chronic obstructive pulmonary disease and asthma; and diabetes; are the four main types of NCDs (WHO, 2018; WHO, 2013; Nordqvist, 2011; CDC, n.a., 2013; Cirino, 2011).

NCDs remain the leading causes of mortality worldwide, killing 41 million people each year which is equivalent to $71 \%$ of all deaths globally. WHO 
reported that every year, 15 million people between the ages of 30 and 69 years die from NCD and over $85 \%$ of these "premature" deaths occur in low- and middle- income countries. Cardiovascular diseases account for most NCD deaths, or 17.9 million people annually, followed by cancers (9.0 million), respiratory diseases (3.9million), and diabetes (1.6 million). With this current trend, progress towards the 2030 Agenda for Sustainable Development is threatened, specifically the target of reducing premature deaths from NCDs by $25 \%$ in 2025 and one-third by 2030 (WHO, 2018).

Moreover, NCDs also account for more than half of the global burden of disease preventing people from living a long life in full health. The total burden of disease is measured both from years of life lost and years lived with disability (KFF, 2019; Roser, M. \& Ritchie, H., 2018; IHME, 2018). Poverty is also closely linked with NCDs. The rapid rise in NCDs is predicted to impede poverty reduction initiatives in low-income countries, particularly by increasing household costs associated with health care. In low-resource settings, health-care costs for NCDs quickly drain household resources. The exorbitant costs of NCDs, including often lengthy and expensive treatment and loss of breadwinners, force millions of people into poverty annually and stifle development (WHO, 2018).

As stated by the UN Philippines Resident Coordinator, Ola Almgren, NCDs have great social and economic impact on individuals and countries and are now considered as a major challenge for sustainable development (Lalu, 2018; WHO, 2018). There is a need to prevent and treat NCDs to achieve quality of life and long term survival and according to WHO (2018), an important way to combat NCDs is to focus on the risk factors associated with these diseases.

Unhealthy eating is one of the major risk factors for NCDs, thus promoting healthy dietary practices would aid in controlling NCDs (WHO, 2018; WHO, 2013; Nordqvist, 2011; CDC, n.a., 2013; Cirino, 2011). Several Food-based Dietary Guidelines (FBDGs) have been established in the Philippines for health promotion and disease control and prevention. These science-based policy guidelines or recommendations provide clear dietary advice on food rather than nutrition as well as easy-tounderstand technical nutrition information to educate individual consumers (EFSA, 2010; Kuizon, et al., 1990; Tanchoco, 2011; Tee, et al., 2016). FBDGs in the Philippines include the Nutritional Guidelines for Filipinos (NGF), Daily Nutritional Guide Pyramid (DNGP), Kumainments, and Pinggang Pinoy.

NGF is a set of dietary guidelines based on Filipinos' eating pattern, lifestyle, and health status. The first nutritional guidelines created in 1990 consisted of five messages only. In 2000, a revised NGF composed of 10 messages was released. Years after, the 2000 version was again revised by the technical working group led by the Food and Nutrition Research Institute of the Department of Science and Technology (FNRI-DOST) which resulted to the 2012 NGF that now includes the basis and justification for each of the 10 key messages (FNRI-DOST, n.d., 2015).

On the other hand, DNGP is a visual translation of the NGF presenting levels of recommended daily consumption of different food groups. Those at the bottom of the pyramid like whole grains and vegetables should be eaten more, while those at the topmost such as fats, and oils, sugar, and red meat should be eaten the least. Messages about exercise and personal and environmental hygiene practices that are slightly separated at the bottom of the pyramid serve as support messages (FAO, n.d., 2014; DOH, n.d., 2020).

The FBDGs in the country also include Pinggang Pinoy which uses a familiar plate model to show the relative proportion of major food groups (rice and alternatives, fish and alternatives, and vegetables and fruits) - in a plate on a per-meal basis. It was developed as a complement to the DNGP $(\mathrm{DOH}$, n.d., 2020).

Lastly, the Kumainments is the popularized version of the revised NGF. It consists of 10 shortened and simplified messages of the NGF for better recall and understanding at the barangay and household levels (NNC, 2015).

Another major risk factor in the development of NCDs is physical inactivity (WHO, 2018). Regular physical activity is a well-established protective factor for the prevention and treatment of the leading NCDs and it also improves mental health, delays the onset of dementia and improves quality of life and well-being. However, in the University of the Philippines Open University (UPOU), a sedentary work lifestyle can be observed. As all courses offered in the university are delivered online, most of the employees spend long hours (at least eight hours) at the office sitting in front of a computer screen and not engaging in any physical activity. An infographic from Online University has also presented that a sedentary job "kills" employees as it slows their metabolism, promotes obesity and increases rates of death from heart disease (Online University, 2012). A study by Kurniawan et al. (2018) also revealed that university staffs have a greater risk of developing NCDs such as cardiovascular diseases and diabetes and have a more unsatisfactory work quality. In order to address this health concern, the UPOU Health and Wellness Committee conducts various physical activities for its employees before and after work hours. They do volleyball, basketball and dancercise sessions twice a week and short warm-up exercises during flag ceremony at the start of every week.

Although workplace physical activity programs are increasingly proposed or being conducted to increase physical activity levels of employees in UPOU, sitting and screen time remain extremely high. The most realistic and effective things sedentary workers can do to avoid the consequences of not engaging in any, or very little, physical activity 


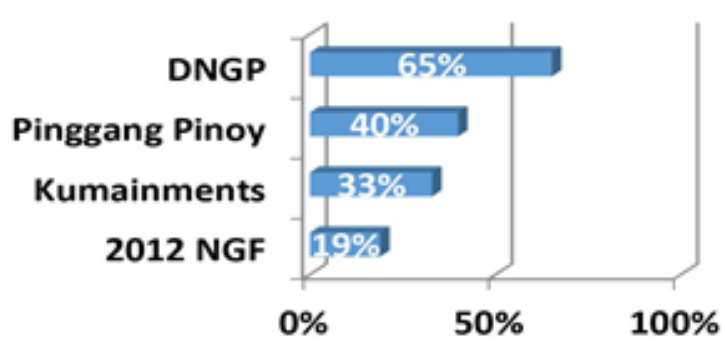

Figure 1. Distribution of respondents by awareness of FBDGs

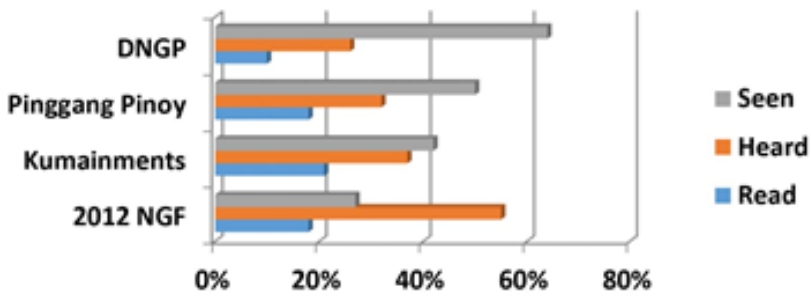

Figure 2. Distribution of respondents by level of awareness of FBDGs

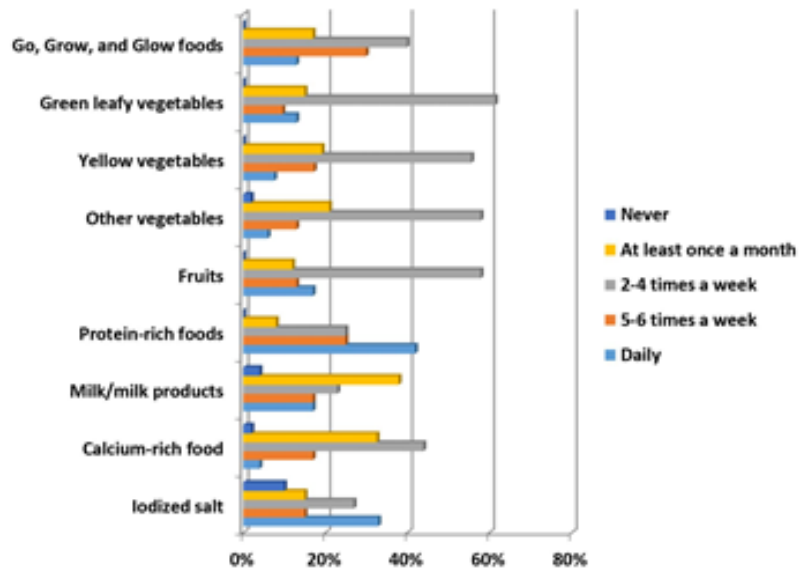

Figure 3. Distribution of reactions to the positive practice statements

for eight or more hours a day is to practice healthy eating habits (Williams, 2018; Gulbin, n.d., 2011). Even if they do not have a lot of flexibility in terms of being active on the job, they do have control over the food and drinks they are consuming throughout their day. Even in meetings/activities inside or outside the university, food served are decided by employees themselves, mostly the administrative staff. Thus, it is really important for UPOU employees to be aware of and to practice healthy eating behaviors. This study determined their awareness of FBDGs, eating practices relative to the nutritional guidelines, and preferred sources of information about healthy eating.

As most of the health programs or activities being implemented in UPOU under its Team Approach and Youthful Outlook (TAYO) flagship program do not focus on food and nutrition, this research study would very much benefit the university. The study's results and recommendations would guide the UPOU Health and Wellness Committee in developing nutrition-related programs/activities aimed at promoting healthy eating practices among UPOU employees.

\section{Methods}

The study used the survey research design to gather data from the respondents. All 150 employees were asked to participate in the study excluding those with specific health conditions like hypertension and diabetes. A total of 85 healthy employees aged 19-59 years old were able to complete the online adapted survey which includes questions on awareness of the four FBDGs-2012 NGF; Kumainments (simplified version of NGF); Daily Nutritional Guide Pyramid (DNGP); and Pinggang Pinoy (a plate-like pictorial model), eating practices 


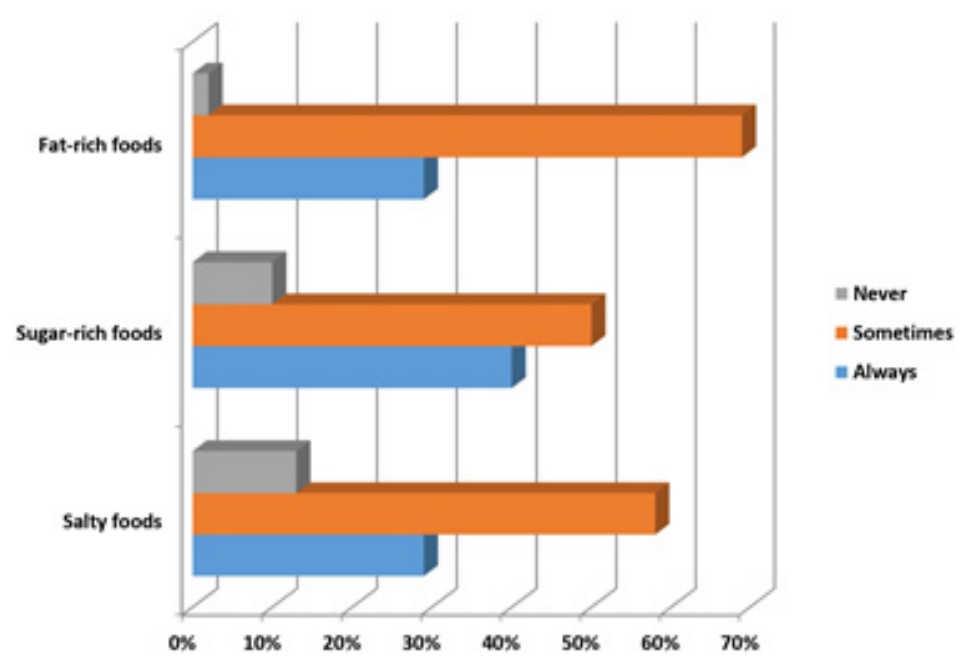

Figure 4. Distribution of reactions to the positive practice statements

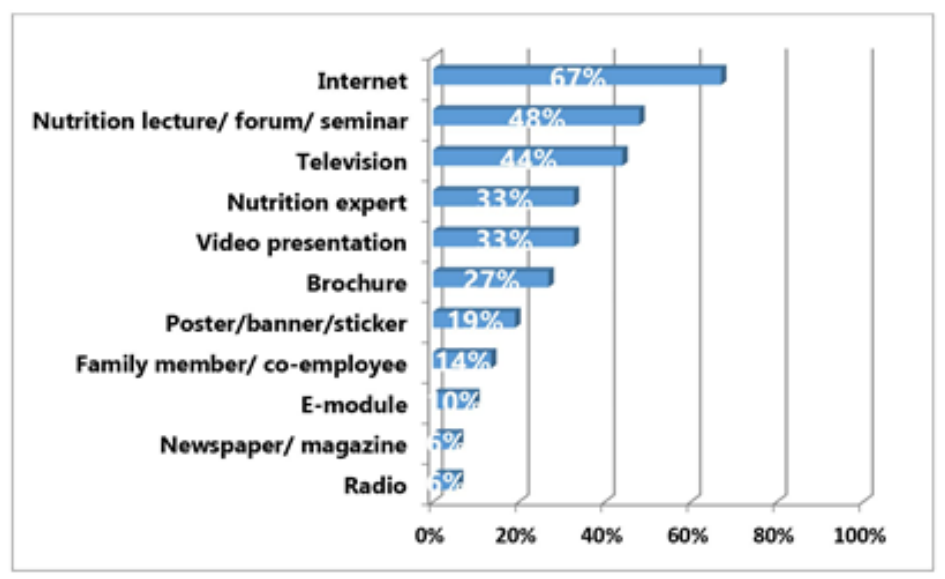

Figure 5. Distribution of respondents by preferred sources of information

relative to the $2012 \mathrm{NGF}$, and preferred sources of information on the FBDGs (Lopez-Madrid, et al., 2018). Pretesting was done prior to the use of the tool in the study. To eliminate response bias, the study ensured anonymity and confidentiality of the responses. Other ethical issues such as informed consent, beneficence, and non-maleficence were also taken into consideration. Clearance from the ethical review board of FMDS was sought prior to the implementation of the research. Data were analyzed using descriptive statistics such as frequency counts and percentages and measures of central tendency (median, mode).

\section{Results}

\section{Awareness of the FBDGs}

As can been seen in Figure 1, majority (65\%) of the respondents have seen, heard, or read the Daily Nutritional Guide Pyramid (DNGP). However, only a minority were aware of the Pinggang Pinoy
(40\%), Kumainments (33\%), and 2012 Nutritional Guidelines for Filipinos (NGF) (19\%).

Among those who were aware, only a few have read the FBDGs. Figure 2 shows that most of the respondents have only seen or heard about the DNGP (90\%), Pinggang Pinoy (82\%), Kumainments (79\%), and 2012 NGF (82\%).

\section{Eating Practices}

As shown in Figure 3, most (87\%) of the respondents do not eat a variety of food (Go, Grow, Glow) daily. Moreover, most of the respondents consume green leafy vegetables $(77 \%)$, yellow vegetables $(75 \%)$, other vegetables $(79 \%)$, fruits $(70 \%)$, milk or milk products $(61 \%)$, and other calcium-rich foods $(77 \%)$ only 2-4 times a week or at least once a month. Majority of the respondents also only sometimes limit their consumption of fat-rich and high in cholesterol foods $(69 \%)$, sugar-rich foods $(50 \%)$, and salty foods $(58 \%)$. 


\section{Preferred Sources of Information}

Figure 4 presents the distribution of respondents by their preferred sources of information on healthy eating or FBDGs. Their top two most preferred sources of information were the internet $(67 \%)$ and nutrition lecture/forum/seminar $(48 \%)$, followed by television $(44 \%)$, nutrition expert $(33 \%)$, and video presentation $(33 \%)$.

\section{Discussion}

Only a minority of the respondents were aware of the Pinggang Pinoy (40\%), Kumainments (33\%), and 2012 Nutritional Guidelines for Filipinos (NGF) (19\%). Among those who were aware, only a few have read the FBDGs. These findings suggest increasing UPOU employees' level of awareness of the FBDGs to be able to adhere to the guidelines and practice healthy eating behaviors. According to a study by Bechthold et al. (2017), awareness of the FBDGs is indispensable to encourage people's performance of desired behaviors.

The respondents also generally reported unfavourable eating practices with almost all of the statements being practiced infrequently. Most (87\%) of the respondents do not eat a variety of food (Go, Grow, Glow) daily. This is consistent with the 2013 National Nutrition Survey (NNS) where it was found that Filipino's meal pattern only consisted of rice and fish or rice and vegetables (FNRI-DOST 2015). Similar also to the results of the 2013 NNS, most of the respondents consume green leafy vegetables $(77 \%)$, yellow vegetables $(75 \%)$, other vegetables $(79 \%)$, fruits $(70 \%)$, milk or milk products $(61 \%)$, and other calcium-rich foods $(77 \%)$ only $2-4$ times a week or at least once a month. Factors such as high cost of nutritious foods like vegetables and fruits, limited access to fresh foods, and lack of awareness or knowledge about nutrition may have contributed to their low frequency of consumption of these food items (Ball et al., 2003; De Abreu et al., 2014; Fukuta et al., 2008; George et al., 2005). Majority of the respondents also only sometimes limit their consumption of fat-rich and high in cholesterol foods $(69 \%)$, sugar-rich foods $(50 \%)$, and salty foods $(58 \%)$. Such findings indicate that the respondents must be persuaded to limit their intake of these kinds of food every day to prevent cardiovascular diseases.

The results previously discussed suggest communication gaps or entry points: UPOU employees must be informed about the FBDGs and must be persuaded to adhere to these dietary guidelines. To help address these issues or bridge the gaps, communication interventions can be conducted (FAO, 2014). Results of this study showed that the respondents' top two most preferred sources of information were the internet $(67 \%)$ and nutrition lecture/forum/seminar (48\%), followed by television (44\%), nutrition expert (33\%), and video presentation (33\%). These sources of information can be used in future health communication interventions that will be conducted in the university to promote healthy eating behaviors among UPOU employees.

\section{Conclusion}

Results of the study showed that most of the respondents were not aware of the FBDGs. Among those who were aware, only a few have read the FBDGs. Adherence to the guidelines was also low as reflected by a very low percentage of respondents practicing the messages on the recommended frequency of intake of food groups. Programs that would increase UPOU employees' awareness of FBDGs and healthy eating practices could be implemented. Based on the results, the UPOU Health and Wellness Committee could conduct nutrition lectures or seminars and invite an expert to serve as resource person. Video presentations could serve as supporting materials in the lecture. As the respondents mostly prefer to get nutrition information on the internet, the lecture/s could also be uploaded in UPOU's online repository of multimedia resources-the UPOU Networks. The university could also produce more video materials about food and nutrition and upload them at the UPOU Networks site as well as in their social media sites to promote healthy eating practices among UPOU employees and ensure a healthy and sustainable workforce. This study may also be conducted in similar institutions where there are no existing communication programs for employees focusing on food and nutrition.

As for the limitations of the study, the very nature of the survey research design means relying on the honesty of the respondents. According to Mauldin (1965), verbal and non-verbal behavior do not go hand in hand. That means that the statement of a person does not necessarily reflect his or her actions (Hauser, 1967). To counter this reliability issue, the researcher did a review of employees' health records at work. The records would reveal the health condition of employees which reflects their actual eating practices.

\section{References}

Ball, K., Mishra, G., Thane, C., \& Hodge, A. (2003). How well do Australian women comply with dietary guidelines? Public Health Nutrition 7(3), 443-452. https://doi.org/10.1079/ PHN2003538

Bechthold, A., Wendt, I., Laubach, B., Mayerbock, C., \& Oberritter H., (2017). Consumers' awareness of food-based dietary guidelines in Germany. Ernaehrungs Umschau international, 64(7), 112-119. https://doi.org/10.4455/eu.2017.025.

Berrian, F.K. (1968). General and social systems. New Brunswick. Rutgers University Press.

Bertalanffy, L.V. (1968). General systems theory. Braziller.

Center for Disease Control and Prevention. (2013). 
Overview of noncommunicable diseases and related risk factors. Retrieved January 16, 2021, from https://www.cdc.gov/globalhealth/ healthprotection/fetp/training_modules/new-8/ overview-of-ncds_ppt_qa-revcom_09112013. pdf

Cirino, E. (2018, June 13). Most common noncommunicable diseases. Healthline. Retrieved January 5, 2021, from https://www. healthline.com/

De Abreu, D., Guessous, I., Gaspoz, J., \& MarquesVidal, P. (2014). Compliance with the Swiss Society for nutrition's dietary recommendations in the population of Geneva, Switzerland: A 10 year trend study (1999-2009). Journal of the Academy of Nutrition and Dietetics, 114(5), 774-780. https://doi.org/10.1016/j. jand.2013.07.032

Department of Health. (2020). Pinggang Pinoy: Healthy Food Plate for Filipino Adults. Retrieved January 16, 2021, from https://doh. gov.ph/node/223

European Food Safety Authority Panel on Dietetic Products, Nutrition, and Allergies (NDA). (2010). Scientific Opinion on establishing foodbased dietary guidelines. EFSA Journal, 8(3). https://doi.org/10.2903/j.efsa.2010

Food and Agriculture Organization of the United Nations (FAO). (2014). Communication for Rural Development Sourcebook. Dover Publications, Inc.

Food and Agriculture Organization of the United Nations (FAO). (2012). Food-based dietary guidelines - Philippines. Retrieved January 6, 2021, from: http://www.fao.org/nutrition/ education/food-dietary-guidelines/regions/ philippines/en/

Food and Nutrition Research Institute - Department of Science and Technology. (2012). Nutritional guidelines for Filipinos: A prescription to good nutrition. Retrieved January 6, 2021, from https://www.fnri.dost.gov.ph/index.php/ publications/writers-pool-corner/57-foodand-nutrition/204-nutritional-guidelines-forfilipinos-a-prescription-to-good-nutrition

Food and Nutrition Research Institute - Department of Science and Technology. (2015). Philippine nutrition facts and figures 2013. 8th National Nutrition Survey: Dietary Survey.

Fukuta, E., Sudo, N., \& Kato, N. (2008). Barriers to compliance with the daily food guide for children among first-grade pupils in a rural area in the Philippine Island of Mindanao. European Journal of Clinical Nutrition, 62, 502-510. https://doi.org/10.1038/sj.ejcn.1602734

George, G., Milani, T., Hanss-Nuss, H., \& Freeland-Graves, J. (2005). Compliance with the dietary guidelines and relationship to psychosocial factors in low-income women in late postpartum. Journal of the Academy of Nutrition and Dietetics, 105, 916-926. https:// doi.org/10.1016/j.jada.2005.03.009
Gulbin, S. (2011). Healthy food for the sedentary worker. Retrieved January 6, 2021, from https://healthfully.com/404322-healthy-foodfor-the-sedentary-worker.html

Hauser, P. M. (1967). The limitations of KAP surveys. social research in developing countries. John Wiley \& Sons Ltd.

Institute for Health Metrics and Evaluation. (2018). Global burden of disease study 2017. Retrieved January 12, 2021, from http://www.healthdata. org/sites/default/files/files/policy_report/2019/ GBD_2017_Booklet.pdf

Kaiser Family Foundation. (2019, January 29). The U.S.government and global non-communicable disease efforts. Retrieved January 6, 2021, from https://www.kff.org/global-health-policy/ fact-sheet/the-u-s-government-and-globalnon-communicable-diseases/

Kreps, G.L. (1990). Communication and health education. In E. Berlin Ray \& L. Donohew (Eds.), Communication and health: Systems and applications (pp. 187-203). Hillsdale, Erlbaum.

Kuizon, M.D., Florentino, R.F., \& Magsaysay, C.G. (1990). Development of Nutritional Guidelines for Filipinos. Journal of Nutritionist-Dietitians Association of the Philippines, 4(3), 103-109.

Kurniawan, T., Afrimasari, E., \& Hartati, S. (2018). Type 2 Diabetes Mellitus Risk Level, Cardiovascular Diseases Risk Level, and Quality of Work Life among University Staffs; Correlational Study. Padjadjaran Nursing Journal, 6(2), 120-130. https://doi. org/10.24198/jkp/v6i2.628

Lalu, G.P. (2018, May 19). DOH: One of every 3 Filipinos dies from non-communicable diseases. Inquirer.net. Retrieved January 3, 2021, from https://newsinfo.inquirer.net/.

Lopez-Madrid, M., Acuin, C., Orense, C., Duante, C., Tan, R., \& Capanzan, M. (2018). Awareness of and Adherence to the Food Based Dietary Guidelines Among Household Meal Planners in the Philippines. Philippine Journal of Science, 147(3), 523-535. https://doi.org/ 10.1079/PHN2003538

Mauldin, L. B. (1965). Verbal and Non-Verbal Behaviors. Retrieved December 21, 2020, from https://books.google.com.ph/s?id=T wrHnls5zwEC\&pg=PA66\&lpg =PA66\&dq $=$ Mauldin+on+verbal+and+nonverbal+be havior \&source $=$ bl\&ots $=$ jaDrt8dco $\&$ sig $=F$ xNnP512BtKSKXTpxFLR7THrwi4\&hl=eK ze0Q6AEIITAA\#v=onepage $\& q=$ Mauldin $\% 20$ on $\% 20 v \quad$ erbal\%20and\%20non-verbal\%20 behavior\&f=false

Modesto, C.A. (2018, October 27). Funds vs NCDs sought in health care program. The Manila Times. Retrieved December 21, 2020, from https://www.manilatimes.net/

National Nutrition Council. (2015, April 28). 10 Kumainments Collaterals. Retrieved January 6, 2021, from https://www.nnc.gov.ph/40- 
10-kumainments/195-10-kumainmentscollaterals.

Nordqvist, C. (2011, April 27). Non-Communicable Disease deaths increasing globally, especially in developing nations. Medical News Today. Retrieved January 3, 2021, from https://www. medicalnewstoday.com/

Online University. (2012, March). Why your job is killing you. Retrieved January 6, 2021, from https://www.payscale.com/careernews/2012/03/your-job-is-killing-you

Roser, M. \& Ritchie, H. (2018, February). Burden of disease. Retrieved December 21, 2020, from https://ourworldindata.org/burden-of-disease

Tanchoco, C.C. (2011). Food-based dietary guidelines for Filipinos: Retrospects and prospects. Asia Pacific Journal of Clinical Nutrition, 20(3), 462-471.

Tee, E.S., Hardinsyah, R., Florentino, R.F, Ismail, M.N., Suthutvoravut, U., \& Hop, L.T. (2016).
Food-based dietary guidelines of Southeast Asian Countries: Part 1- A compilation and analysis of key messages. https://doi. org/10.3177/jnsv.61.s214

Williams, S. (2018, January 26). How to be healthier if you work a sedentary job. Retrieved January 3, 2021, from https://thriveglobal.com/stories/ how-to-be-healthier-if-you-work-a-sedentaryjob/

World Health Organization [WHO]. (2013, March). 10 facts on Noncommunicable Diseases.. Retrieved December 12, 2020 , from https://www.who.int/features/factfiles/ noncommunicable_diseases/en/

World Health Organization [WHO]. (2018, June 1). Noncommunicable Diseases. Retrieved December 12, 2020, from https://www. who.int/news-room/fact-sheets/detail/ noncommunicable-diseases। 